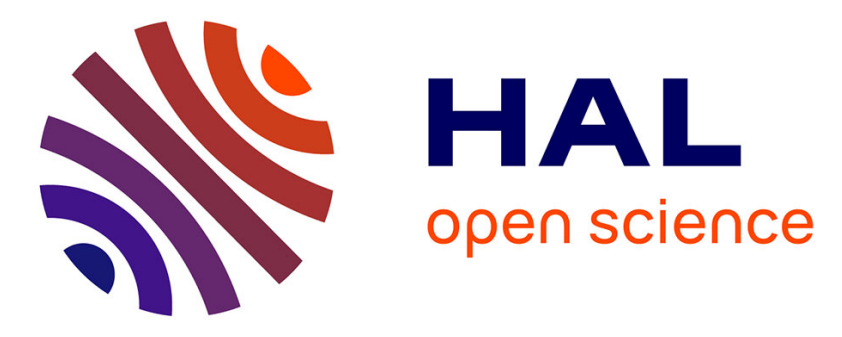

\title{
A microtip self-written on a vertical-cavity surface-emitting laser by photopolymerization
}

Véronique Bardinal, Benjamin Reig, Thierry Camps, Emmanuelle Daran, Jean-Baptiste Doucet, Colette Turck, J.P. Malval, D.-J. Lougnot, Olivier Soppera

\section{To cite this version:}

Véronique Bardinal, Benjamin Reig, Thierry Camps, Emmanuelle Daran, Jean-Baptiste Doucet, et al.. A microtip self-written on a vertical-cavity surface-emitting laser by photopolymerization. Applied Physics Letters, 2010, 96, pp.051114-1. 10.1063/1.3303980 . hal-01158950

\section{HAL Id: hal-01158950 https://hal.science/hal-01158950}

Submitted on 11 Jan 2018

HAL is a multi-disciplinary open access archive for the deposit and dissemination of scientific research documents, whether they are published or not. The documents may come from teaching and research institutions in France or abroad, or from public or private research centers.
L'archive ouverte pluridisciplinaire HAL, est destinée au dépôt et à la diffusion de documents scientifiques de niveau recherche, publiés ou non, émanant des établissements d'enseignement et de recherche français ou étrangers, des laboratoires publics ou privés. 


\title{
A microtip self-written on a vertical-cavity surface-emitting laser by photopolymerization
}

\author{
V. Bardinal, ${ }^{1, a)}$ B. Reig, ${ }^{1}$ T. Camps, ${ }^{1}$ E. Daran, ${ }^{1}$ J. B. Doucet, ${ }^{1}$ C. Turck, ${ }^{2}$ J. P. Malval, ${ }^{2}$ \\ D. J. Lougnot, ${ }^{2}$ and O. Soppera ${ }^{2}$ \\ ${ }^{1} L A A S$, CNRS, 7 Avenue du colonel Roche, F-31077 Toulouse, France and UPS, INSA, INP, ISAE, LAAS, \\ Université de Toulouse, F-31077 Toulouse, France \\ ${ }^{2}$ Institut de Science des Matériaux de Mulhouse (IS2M), CNRS LRC 7228, Université de Haute-Alsace, \\ 15 rue Jean Starcky, BP 72005, F-68058 Mulhouse, France
}

(Received 4 December 2009; accepted 30 December 2009; published online 3 February 2010)

\begin{abstract}
We present the integration of a self-aligned microtip on a vertical-cavity surface-emitting laser (VCSEL) by near infrared photopolymerization. This one-step fabrication process is triggered by the laser source itself. It is based on the use of photopolymers sensitive at the lasing wavelength and can be applied to VCSEL devices after their process fabrication. We have characterized the fabricated microtips and shown that they focus laser light at few micrometers from the device. The applications of this simple method may concern VCSEL beam shaping as well as the fabrication of microprobes for near-field optical microscopy. (c) 2010 American Institute of Physics. [doi:10.1063/1.3303980]
\end{abstract}

VCSELs (vertical cavity surface-emitting lasers) are now key light sources for photonic interconnects and for instrumentation and sensing applications. The potentialities which have already been demonstrated as well as the flexibility of these laser devices have recently strongly contributed to the rise of extended applications related to microsystems and in particular to biomedical instrumentation. ${ }^{1-4}$ Using VCSELs instead of standard laser diodes provides some inherent advantages for several applications, for example, the systems can be smaller and use two-dimensional source arrays such that multiple, simultaneous experiments can be performed in parallel and at low cost and low power consumption. However, despite a limited far-field beam divergence $\left(\sim 10^{\circ}-25^{\circ}\right)$, these sources have more and more to be associated with micro-optical elements to enhance their optical performances, to increase their coupling efficiency to optical fibers or to meet stringent collimation requirements in microsystem applications. ${ }^{5-7}$ Besides, the fabrication of integrated microtips on VCSELs has become a key issue for the development of probes for near-field scanning optical microscopy and high density data storage. ${ }^{8-10} \mathrm{Up}$ to now, the techniques proposed to integrate microlenses or microtips onto VCSELs imply either a hybrid assembly or a photolithography step, whose precision limits the accuracy of the alignment relatively to the VCSEL source $(\sim 1 \mu \mathrm{m})$. We demonstrate in this Letter that a perfectly self-aligned microtip can be formed on the surface of a VCSEL, without any external source, by means of its own beam and that it can be used as a focusing lens. This could pave the way toward advanced laser array probes.

We have developed a specific free-radical photopolymerizable formulation sensitive in the near infra-red (NIR) spectrum. It consists of a mixture of three components: a sensitizer, associated with a coinitiator was used to trigger the polymerization of a triacrylic monomer. Such a monomer exhibits good performances in terms of spatial resolution ${ }^{11}$ and it leads to a cross-linked polymer with suitable mechanical and optical properties for applications in micro-optics. ${ }^{12}$

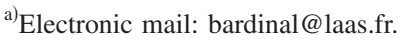

The principles used to formulate the sensitive resin are the following: the dye sensitizer absorbs in the 750-900 nm region. ${ }^{13}$ Upon NIR irradiation, it is photoexcited and reacts with the coinitiator to generate radical species capable of inducing the free-radical polymerization of the monomer. The physicochemical phenomena have already been described in detail. ${ }^{14}$ One major interest of this photopolymer is to become completely transparent after irradiation at the actinic wavelength (photobleaching). This feature is of utmost importance for micro-optics fabrication since the final material has to be transparent at the operating wavelength (typ. $760 \mathrm{~nm}$ ). Moreover, this property ensures complete inertness of the micro-optical elements upon further visible or NIR irradiation after rinsing.

The principle of our method is as follows: the first step consists in the deposition of a photopolymer droplet on top of the VCSEL wafer [Fig. 1(a)]. Second, the VCSEL is electrically driven under probes, leading to a laser emission that induces a local photopolymerization of the resist at room

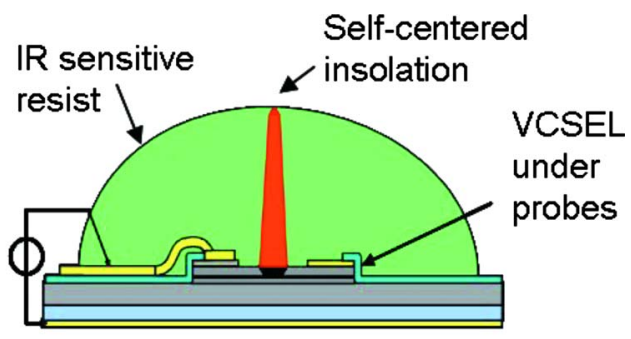

(a)

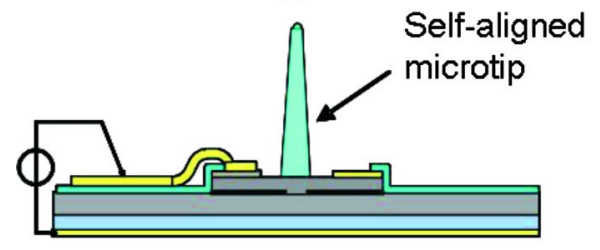

(b)

FIG. 1. (Color online) Principle of microtip fabrication: (a) IR sensitive resist local deposition on the VCSEL wafer followed by IR exposure created by VCSEL emission. (b) Resulting microtip obtained after rinsing. 

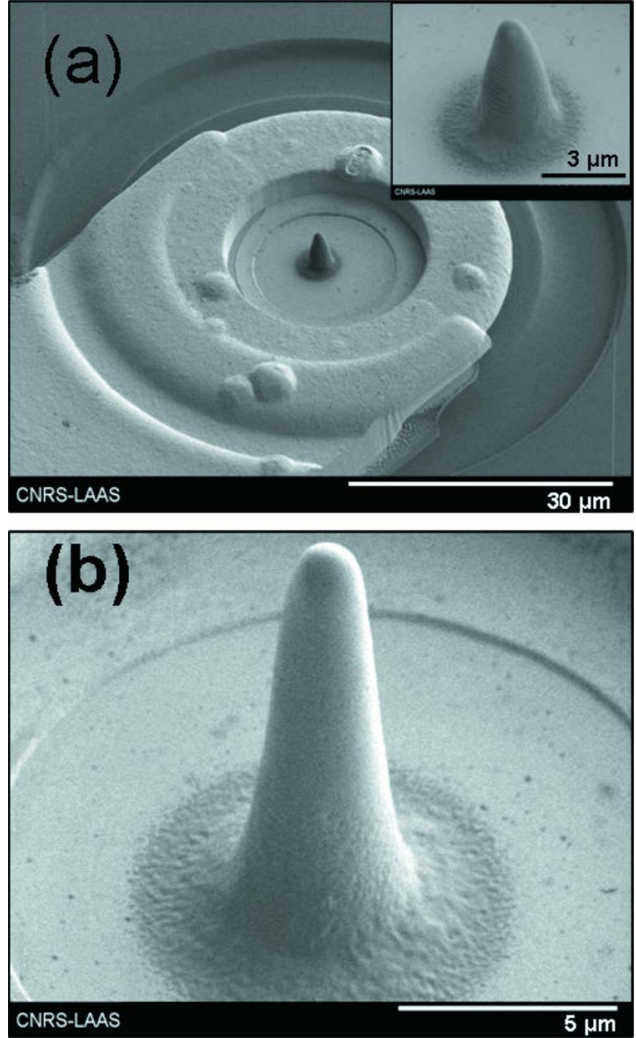

FIG. 2. (Color online) SEM image of a microtip self-written at the center of a $763 \mathrm{~nm}$ single mode VCSEL. (a) The applied current is $0.6 \mathrm{~mA}$ and the resist thickness is $4.2 \mu \mathrm{m}$. Inset: zoom on the microtip. (b) SEM view of a microtip fabricated using the same applied current $(0.6 \mathrm{~mA})$ and a higher resist thickness $(h=8.5 \mu \mathrm{m})$. In both cases, the height of the tip is found to be equal to the initial resist thickness.

temperature. After rinsing the sample, a solid and transparent micro-object remains at the center, perfectly aligned with the VCSEL [Fig. 1(b)] It has to be emphasized that the photopolymerizable formulation is compatible with spin-coating and thereby that a collective fabrication will be possible by applying a collective current injection.

We have implemented this method to standard $760 \mathrm{~nm}$ single-mode VCSELs. The VCSEL wafers used in this study were supplied by Philips Technologie GmbH U-L-M Photonics (Ulm, Germany). These standard oxide-confined devices emit a single-mode beam [side mode suppression ratio $(\mathrm{SMSR})>35 \mathrm{~dB}]$ in the range $[763.5-765 \mathrm{~nm}]$ with a typical threshold current of $0.44 \mathrm{~mA}$. The microtips were fabricated under probes using a standard electro-optic prober. The polymer liquid droplets were deposited on the VCSEL wafer by capillarity from a micropipette. The composition of the NIR photopolymer has been adapted from Ref. 15 which is derived from previous works ${ }^{16-19}$ to take into account the specificities of the microfabrication on VCSELs (adhesion of the polymer, resolution, and final properties of the material) and the molecular aspects of inhibition of freepolymerization by oxygen quenching. The trifunctional monomer was selected to ensure good mechanical properties of the polymer tip (namely rigidity and hardness) and suitable anchoring of the polymer onto the micropipette end.

After polymer deposition, a current just above threshold (0.6 mA) was applied. In these conditions, a microtip was immediately formed on the VCSEL surface (within one second). For this current, the emitted power is $50 \mu \mathrm{W}$ and the
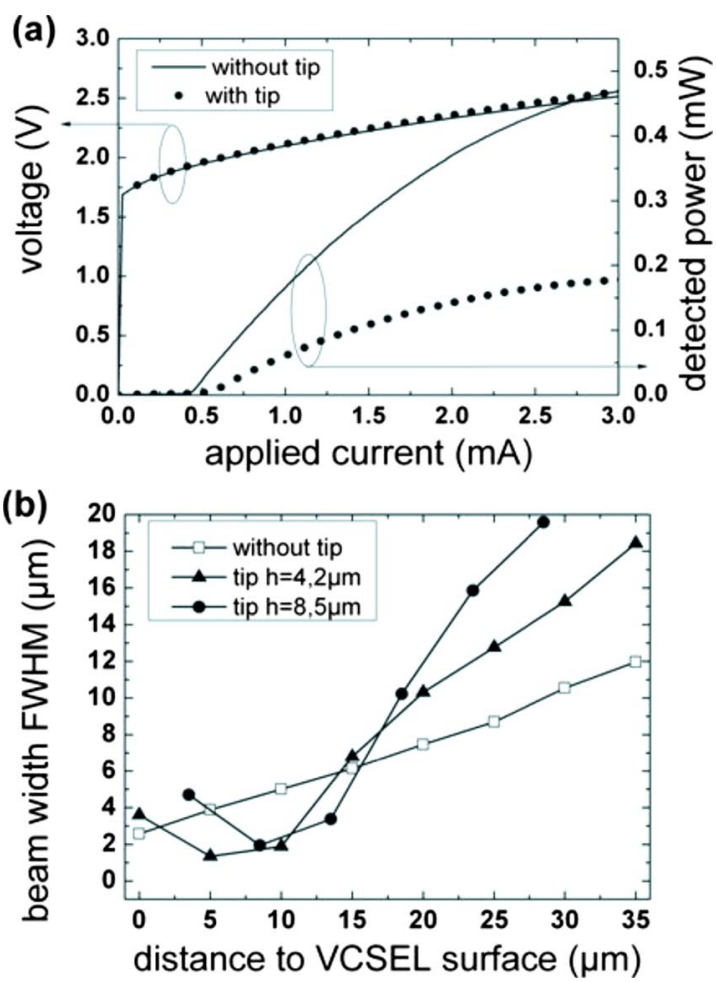

FIG. 3. (Color online) (a) $\mathrm{cw} L-I-V$ characteristics measured under probes for a VCSEL device without tip (straight curves) and with an integrated tip (4.2 thick/dotted curves). (b) Beam spot width measured in function of the distance to the VCSEL surface for two tips created with two different resist thicknesses: $h=4.2 \mu \mathrm{m}$ (circles) and $h=8.5 \mu \mathrm{m}$ (triangles) and compared to a reference sample with no tip (squares).

emission surface is estimated to be $16 \mu \mathrm{m}^{2}$. Consequently the optical intensity is roughly equal to $3.1 \mu \mathrm{W} / \mu \mathrm{m}^{2}$. Scanning electron microscopy (SEM) images of the obtained microtip can be observed in Fig. 2(a). The basis diameter of the tip is equal to $3.5 \mu \mathrm{m}$, which corresponds roughly to the VCSEL emission extent at this current and the curvature radius is estimated to be $0.6 \mu \mathrm{m}$. The tip height corresponds to the initial photopolymer droplet thickness (in this case, $4.2 \mu \mathrm{m}$ ), demonstrating that all the resist material has polymerized. As seen on SEM images [inset in Fig. 2(a)], the top surface is smooth, although some circular fringes can be observed on the tip sides, probably due to optical interferences occurring during the infrared photopolymerization process. A longer tip was obtained in the same conditions by using a higher polymer thickness $(8.5 \mu \mathrm{m})$ [Fig. 2(b)].

The measurement of the $\mathrm{cw}$ light-current $(L-I)$ and voltage-current $(I-V)$ characteristics was carried out before and after tip fabrication [Fig. 3(a)]. The electrical properties are found unchanged, while the laser threshold of the device is slightly increased (i.e., $0.53 \mathrm{~mA}$ instead of $0.44 \mathrm{~mA}$ ). We attribute this behavior to the presence of the resist layer above the device that leads to a lower top reflectivity of the microcavity laser and to a slight modification of lasing conditions. Second, the total detected power is lower than the initial one ( $37 \%$ in the case of the $4.2-\mu \mathrm{m}$-thick tip) because our detector was placed at a distance of $3 \mathrm{~mm}$ from the device under probes and thus only intercepts a part of the light. Indeed, optical modeling taking into account the conic shape of the tip and Gaussian optics propagation (Zemax$\mathrm{EE})$ points out that the tip focuses at least $60 \%$ of the initial beam at few micrometers from the surface. The calculated 
waist positions are located at $1.3 \mu \mathrm{m}$ from the tip surface (for the $4.2-\mu \mathrm{m}$-thick tip) and $1.2 \mu \mathrm{m}$ (for the $8.5-\mu \mathrm{m}$ thick), with corresponding beam divergences of $33^{\circ}$ and $38^{\circ}$, respectively. Therefore, it leads at $3 \mathrm{~mm}$ to a partial detection of $39 \%$ in the case of the $4.2-\mu \mathrm{m}$-thick tip.

To confirm this assumption, the evolution of the beam spot size was measured versus the distance to the VCSEL surface using a $50 \times$ near infrared treated microscope objective. The results were compared to those of a reference device without tip. For the two tips, the beam width is reduced by a factor higher than 2. As shown in Fig. 3(b), this focusing effect is observed at distances in good agreement with those estimated by the optical modeling. These first results constitute a clear demonstration of the focusing capabilities of these microtips.

To conclude, we have demonstrated that it is possible to fabricate self-aligned microtips on VCSELs devices using a NIR photopolymer and a single-step process suitable with mass production. The geometry of the tips can be modified by the resist thickness and by the emission properties of the VCSEL. The characterizations we have carried out show that these tips allow to focus laser light at short distances (few micrometers). Future work will deal with the thorough investigation on how chemical and electrical parameters influence the tip geometry. This is of paramount importance in view of exploiting this approach for beam collimation, coupling to optical fibers, or mode filtering applications, as well as for the extension of this method to longer wavelengths.

The authors would like to acknowledge Franck Carcenac for assistance on SEM measurements, Guilhem Almuneau for discussions on optical characterizations, and Corinne Vergnenègre and Pierre Assus (from OCA, Nice) for help in optical modeling. The French National Research Agency (ANR) is gratefully acknowledged for financial support (Grant No. ANR-09-BLAN-0168-01).
${ }^{1}$ E. Thrush, O. Levi, W. Ha, G. Carey, L. J. Cook, J. Deich, S. J. Smith, W. E. Moerner, and J. S. Harris, Jr., IEEE J. Quantum Electron. 40, 491 (2004).

${ }^{2}$ A. L. Birkbeck, R. A. Flynn, M. Ozkan, D. Song, M. Gross, and S. C. Esener, Biomed. Microdevices 5, 47 (2003).

${ }^{3}$ A. Kroner, I. Kardosh, F. Rinaldi, and R. Michalzik, Electron. Lett. 42, 93 (2006).

${ }^{4}$ A. Kroner, F. Rinaldi, R. Rosch, and R. Michalzik, Electron. Lett. 44, 353 (2008).

${ }^{5}$ A. M. Kasten, J. D. Leisher, D. K. Mac Elfresh, D. Vacar, and K. D. Choquette, IEEE J. Sel. Top. Quantum Electron. 14, 1123 (2008).

${ }^{6}$ L. Lechuga, J. Tamayo, M. Alvarez, L. G. Carrascosa, A. Yufera, R. Doldan, E. Peralias, E. Rueda, J. A. Plaza, K. Zinoviev, C. Dominguez, A. Zaballos, M. Moreno, C. Martinez-A, D. Wenn, N. Harris, C. Bringer, V. Bardinal, T. Camps, C. Vergnenègre, C. Fontaine, V. Diaz, and A. Bernad, Sens. Actuators B 118, 2 (2006).

${ }^{7}$ A. Nallani, T. Chen, J.-B. Lee, D. Hayes, and D. Wallace, Proc. SPIE 5836, 116 (2005)

${ }^{8}$ C. Levallois, V. Bardinal, T. Camps, T. Leichlé, E. Daran, J. B. Doucet, and C. Vergnenègre, Proc. SPIE 6992, 69920W (2008).

${ }^{9}$ S. Heisig, O. Rudow, and E. Oesterschulze, Appl. Phys. Lett. 77, 1071 (2000).

${ }^{10}$ D. Heinis, C. Gorecki, C. Bringer, V. Bardinal, T. Camps, J.-B. Doucet, P. Dubreuil, and C. Fontaine, Jpn. J. Appl. Phys., Part 2 42, L1469 (2003).

${ }^{11}$ K. Goto, Y.-J. Kim, S. Mitsugi, K. Suzuki, K. Kurihara, and T. Horibe, Jpn. J. Appl. Phys., Part 1 41, 4835 (2002).

${ }^{12}$ H. I. El Ahrach, R. Bachelot, A. Vial, G. Lerondel, J. Plain, P. Royer, and O. Soppera, Phys. Rev. Lett. 98, 107402 (2007).

${ }^{13}$ R. Bachelot, P. Royer, G. Wurtz, C. Ecoffet, A. Espanet, and D. J. Lougnot, French Patent No. PCT 9814385 (2001).

${ }^{14}$ C. Carré, C. Reichardt, and D. J. Lougnot, J. Chim. Phys. Phys.-Chim. Biol. 84, 577 (1987).

${ }^{15}$ O. Soppera, S. Jradi, and D. J. Lougnot, J. Polym. Sci. A Polym. Chem. 46, 3783 (2008).

${ }^{16}$ O. Soppera, C. Turck, and D. J. Lougnot, Opt. Lett. 34, 461 (2009).

${ }^{17}$ N. Noiret, C. Meyer, and D. J. Lougnot, Pure Appl. Opt. 3, 55 (1994).

${ }^{18}$ E. Watanabe, M. Kawabata, and I. Sumiyoshi, U.S. Patent No. 5,496,903 (1996).

${ }^{19}$ T. Urano, H. Nagasaka, M. Shimizu, and T. Yamaoka, J. Imaging Sci. Technol. 41, 407 (1997). 